\title{
A erótica de Utagawa Kunisada e a cultura das quatro estações
}

\author{
Giovanna Maia Tavares de Almeida*
}

DOI: 10.11606/issn.2318-8855.v9i1p289-317

Resumo: Dentre as diversas produções artísticas no Japão do período Edo (16031868) e inseridas no grande gênero ukiyo-e, as "imagens do mundo flutuante", nota-se uma significativa produção de estampas xilográficas e pinturas que contêm material sexualmente explícito ou implícito, as chamadas shunga - em tradução literal, "imagens de primavera", sendo "primavera" uma referência para a atividade sexual. Tais gravuras frequentemente faziam referências a elementos tidos como clássicos dentro da cultura japonesa, em adaptações de narrativas e poemas canônicos para criar uma ambientação visual neste gênero de arte erótica. Dentre esses elementos clássicos, nota-se uma constante representação a respeito das mudanças sazonais em exaltações às quatro estações; nesse sentido, o presente artigo pretende analisar quatro estampas de Utagawa Kunisada (1786-1865) da obra "Contemplação das Quatro Estações do Amor", produzidas entre 1827 e 1829. Por meio de uma análise iconográfica aliada à bibliografia sobre o tema, pretende-se investigar as estratégias do pintor em elaborar uma ambientação visual concentrada nos elementos que compõem a temática erótica bem como as referências às mudanças sazonais.

Palavras-chaves: arte japonesa; História da Arte; período Edo; shunga; ukiyo-e.

\footnotetext{
*Graduanda em História pela Universidade Estadual de Campinas (Unicamp). Aluna de Iniciação Científica, sob orientação da Prof ${ }^{a}$. Dr ${ }^{a}$. Patrícia Dalcanale Meneses. É membro do Grupo de Estudos Okinawanos da Universidade de São Paulo. Agradeço ao CNPq pelo fomento ao projeto que serviu de base a este artigo e à minha orientadora que possibilitou a realização a deste; à Dra . Juliana Pinheiro Maués pela gentileza e grande auxílio em todas as etapas do desenvolvimento deste projeto, desde o seu início; ao (in memorian) Prof. Dr. Koichi Mori pelo fornecimento de materiais que auxiliaram esta pesquisa e pelo apoio na coordenação do Grupo de Estudos Okinawanos; aos pareceristas pelos comentários e sugestões que contribuíram na elaboração deste artigo; e a todos os amigos pelo suporte e incentivo nesta pesquisa. E-mail para contato: giovanna.maia.almeida@gmail.com
} 


\section{artigos}

\section{Giovanna Maia Tavares de Almeida}

\section{Introdução}

Uma das questões interessantes do estudo da História é, certamente, a diversidade de fontes históricas que possibilitam um grande escopo de recortes para a análise. Nesse sentido, a consolidação do campo de História da Arte dentro da metodologia do estudo histórico se mostra como um potencial instrumento: a partir da análise da produção artística de diferentes sociedades, em diferentes recortes temporais, é possível produzir interpretações não apenas culturais, mas ainda econômicas, políticas, religiosas etc. - sobretudo quando associadas entre si, e em comparação com diferentes momentos. Apesar da historiografia da arte tradicionalmente ter um enfoque constante em questões relativas ao Ocidente, a pesquisa de áreas que se distanciem de tal recorte espacial e ideológico é indubitavelmente relevante; e, dentro das questões da arte não-ocidental, verifica-se a arte japonesa, objeto de interesse nesta análise.

$\mathrm{Na}$ arte japonesa se fazem presentes diversas produções artísticas que remontam desde os primórdios desta sociedade e conferem uma abundância de estilos e suportes que abrangem uma infinidade de fontes históricas que contribuem para o seu estudo. Dentre os diversos cenários e movimentos verificados no decorrer de sua história, o contexto artístico do período Edo confere características singulares e expressivas. Compreendido entre os anos de 1603 e 1868, o período Edo teve início com o governo senhorial militarizado formado pelo clã Tokugawa e é frequentemente caracterizado pelas suas mudanças políticas, econômicas e sociais - sobretudo pela ascensão da ordem guerreira, da relativa estabilidade social e consequente crescimento econômico e populacional e ainda pela política de isolamento ${ }^{1}$ perante o

\footnotetext{
${ }^{1}$ Apesar de marcante, as políticas de isolacionismo não podem ser consideradas absolutas - levando em consideração o contato com mercados asiáticos e ainda, o entreposto comercial de Dejima
} 


\section{artigos}

\section{A erótica de Utagawa Kunisada e a cultura das quatro estações}

exterior. Nesse momento, é notado um expressivo desenvolvimento artístico ${ }^{2}$ conferido pela proliferação do teatro kabuki³, da música, da poesia e da literatura - e, sobretudo, das artes conhecidas como ukiyo-e. Traduzido como "as imagens do mundo flutuante", o gênero artístico ukiyo-e é caracterizado por estampas e pinturas de representações de folclore, cenas de viagens, locais famosos de cidades e províncias, flora e fauna, atores e cenas de teatro kabuki, belas mulheres e belos garotos, guerreiros ferozes e heroicos e também pela concentração na temática erótica.

Esta última, conhecida posteriormente como shunga (em tradução literal “imagens da primavera", sendo "primavera" um termo constantemente relacionado com a atividade sexual), refere-se às imagens que contêm material sexualmente explícito ou implícito, de práticas hetero ou homossexuais desde jovens a adultos, normalmente produzidas por meio da técnica da xilogravura, e de formato variado desde pequenas estampas até séries numerosas de grandes livros ilustrados. Embora as estampas sejam frequentemente associadas às produções textuais, sobretudo no caso dos shunpon ${ }^{4}$, de modo algum podem ser consideradas como simples ilustrações: elas transmitem sentidos através da ornamentação, das formas, frequência e da utilização de cores e outros recursos que se destoam das estratégias linguísticas. Num primeiro contato com obras de shunga em sua ampla variedade de formas, cenários, agentes e contextos, há o perigo da interpretação de que essas

controlado pelos holandeses em Nagasaki. Para maior profundidade, ver TOBY, 1977.

2 No período, o entendimento a respeito da arte era significativamente distinto da concepção atual, e, desta forma, essa é uma visão imposta retroativamente. Para maior profundidade, ver OKANO, 2010.

${ }^{3}$ As palavras em japonês foram transcritas de acordo com o sistema Hepburn de romanização, com exceção das já dicionarizadas em português.

${ }^{4}$ De origem semelhante à palavra shunga, os shunpon são livros que contém materiais eróticos - "shun" de "primavera" e "pon", uma variação fonética de hon, livro. 


\section{artigos}

\section{Giovanna Maia Tavares de Almeida}

imagens que retratam explicitamente a atividade sexual fossem usadas exclusivamente como artefatos de homens lascivos - tendo como um simples paralelo a utilização da pornografia na atualidade. É consolidada a interpretação de que suas utilizações variavam em público - entre homens e mulheres, "jovens e adultos, independente de status ou localização, e incluía citadinos e agricultores, assim como

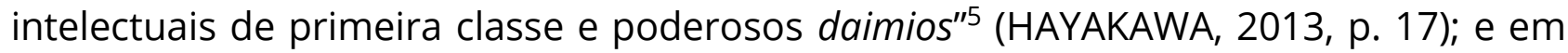
sua utilização, como aponta Hayakawa:

Também popularmente se pensava [as estampas shunga] ter poderes espirituais para afastar incêndios, manter os guerreiros em segurança nas batalhas, aumentar fertilidade, e eram consideradas importantes como um elemento auspicioso de um enxoval de noiva6 (HAYAKAWA, 2013, p. 19).

Apesar da forte apreciação de shunga, sobretudo nas camadas populares e citadinas, e da produção de obras do gênero por - hoje, renomados - pintores como Katsushika Hokusai (1760-1849), Utagawa Hiroshige (1797-1858) e Utagawa Kunisada (1786-1865), a partir da Era Meiji (1868-1912) este tipo de produção sofreu fortes retaliações. Após sucessivas crises internas e na pressão europeia e estadunidense para a abertura política e econômica do Japão, a aristocracia é reestabelecida no poder pelo imperador Meiji (1852-1912); nas décadas seguintes, os esforços para a adequação a preceitos ocidentais a fim de elevar o Japão como potência política, militar e econômica envolviam políticas de rejeição e repressão dos costumes e hábitos do período Edo - e, dentre outros aspectos, uma forte repressão a shunga (AKI e BUCKLAND, 2013, p. 38). De acordo com jornais do período, publicações que

\footnotetext{
${ }^{5}$ No original: "[...] from the young and old, regardless of status or location, and included commoners in the cities, farmers, as well as first-class intellectuals and powerful daimyos". Tradução nossa.

${ }^{6}$ No original: "It was also thought popularly to have spiritual powers to ward off fire, keep warriors safe in battle, and enhance fertility, and it was considered important as an auspicious element of a bridal trousseau". Tradução nossa.

${ }^{7}$ No presente artigo, os nomes próprios japoneses foram grafados na ordem Sobrenome Nome.
} 


\section{artigos}

\section{A erótica de Utagawa Kunisada e a cultura das quatro estações}

continham este tipo de conteúdo eram confiscadas ou destruídas - e seus vendedores eram multados e poderiam ser presos; os números são expressivos: entre o final do século XIX e início do XX, as apreensões desses tipos de material chegaram à casa das dezenas de milhares (AKI e BUCKLAND, 2013, p. 41). Dessa forma, inserida na intenção de afastar a nova era dos costumes do período anterior, a percepção em relação a shunga foi colocada como algo contrário aos preceitos que eram interessantes de serem promovidos, nacional e internacionalmente, para a inserção do Japão no Ocidente como uma potência política, econômica e militar.

Num cenário oposto ao verificado pela repressão no Japão, a circulação de produções artísticas japonesas ganhou espaço nos mercados de arte na Europa, dentre as quais incluem-se obras dos gêneros ukiyo-e e shunga. Vista através de uma lente exotizante, o interesse pela arte japonesa cresceu entre os membros inseridos no cenário artístico de vanguarda na Europa, no qual podem-se destacar nomes como os de Manet (1832-1883) e Whistler (1834-1903); que buscavam, na arte japonesa, aspectos que se distanciavam da realidade estética europeia, como a assimetria de formas e a presença constante de cores fortes. É possível verificar hoje uma forte presença da arte japonesa em acervos de museus e galerias na Europa e nos Estados Unidos, como o British Museum e o Museum of Fine Arts de Boston, o que atesta a importância da inserção de seus preceitos no cenário artístico ocidental desde o século XIX.

Por meio de exibições em grandes museus ${ }^{8}$ e por novas abordagens em História da Arte, o meio acadêmico (seja pela literatura, arte ou história) se esforça para reafirmar o importante lugar da expressão erótica japonesa. Nesse sentido, o

\footnotetext{
8 Destacam-se as exibições sediadas em Helsinki "Forbidden Images: Erotic Art from Japan's Edo" (2002), em Barcelona "Secret Images: Picasso and Japanese Erotic Prints" (2009), no British Museum "Shunga - Sex and Pleasure in Japanese Art, 1600-1900" (2013) e outras.
} 


\section{artigos}

\section{Giovanna Maia Tavares de Almeida}

presente artigo se propõe a realizar uma análise das estampas de Utagawa Kunisada nos livros eróticos intitulados "Contemplação das Quatro Estações do Amor"9, produzidos entre 1827 e 1829.

\section{Período Edo (1603-1868): contextualização política e artística}

A obra em questão se insere no período Edo (Edo jidai), conhecido também como período Tokugawa (Tokugawa jidai). Marcado pelo bakufu de Edo, refere-se a um governo senhorial militarizado formado pelo clã Tokugawa e sediado na cidade de Edo, atual Tóquio. É conhecido ainda como bakufu de Tokugawa, ou xogunato Tokugawa.

Com a ascensão de Tokugawa leyasu (1543-1616) como seii taishōgun (traduzido como "grande general apaziguador de bárbaros"), inicia-se o período em 1603 que se manteve por pouco mais de 250 anos com hegemonia de seu clã. É caracterizado pela concepção de uma estrutura governamental complexa, aliada a um grande desenvolvimento urbano e de expressiva ebulição cultural, com o surgimento de diversas atividades conectadas a novos cenários, e dentre eles, a transferência da capital de Quioto, onde viva a aristocracia, para a capital administrativa do xogunato em Edo - que inicialmente era um vilarejo de pescadores dentro do domínio do clã Tokugawa, permitindo um relativo distanciamento de influência da corte. No que se refere à estratificação social, é relevante pontuar a participação da classe dos comerciantes em relação às artes, já que anteriormente este contato era exclusivo das classes guerreiras, religiosas e aristocráticas; além disso, a ostentação da arte era tida como uma forma de afirmação cultural, já que os

\footnotetext{
9 No original: (Shunka shūtō) Shiki no nagame. Tradução feita por CORDARO, Madalena Natsuko Hashimoto em "A erótica japonesa na pintura \& na escritura dos séculos XVII a XIX" São Paulo: Edusp, 2017.
} 


\section{artigos}

\section{A erótica de Utagawa Kunisada e a cultura das quatro estações}

citadinos não se configuravam no panorama da participação política e do prestígio social. O período é frequentemente associado a suas políticas de relações estrangeiras e seu embate com o exterior, como a proibição do cristianismo e a institucionalização do isolacionismo nacional, chamado de sakoku. Também se nota relativa estabilidade político-social, que teve como reflexo um grande crescimento populacional. Esta relativa estabilidade político-social viria a se alterar por sucessivas crises internas que enfraqueceriam o governo; estes e outros motivos, somados à pressão externa para a abertura dos portos - que teve seu ápice na chegada da armada estadunidense comandada pelo Comodoro Perry em 1854 - levaram ao fim do bakufu com o restabelecimento da aristocracia no poder pelo imperador Meiji, em 1868. Nas décadas seguintes, pontuam-se os esforços para sua inserção no Ocidente como uma potência política, econômica e militar, os quais incluíam políticas de rejeição e repressão dos costumes e hábitos do período Edo, especialmente aqueles ligados à ordem social antiga - como a religião budista, mais identificada à classe guerreira.

No âmbito das artes, no período Edo nota-se um aumento das atividades no século XVII, com a difusão do teatro kabuki, o início da circulação de ukiyo-e e a formação do mercado editorial de publicações impressas. Já no século XIX, durante as eras Bunka e Bunsei (1804-1830), nota-se também a proliferação da literatura, pintura e clubes de poesia, sobretudo devido a um período de prosperidade econômica (BUCKLAND, 2013, p. 129). Obras de pintores foram produzidas neste período, com destaque especial para Katsushika Hokusai e os pintores da escola Utagawa; estes, majoritariamente conhecidos por suas imagens de atores de teatro kabuki, também conquistaram uma posição conhecida na produção de livros eróticos (BUCKLAND, 


\section{artigos}

\section{Giovanna Maia Tavares de Almeida}

2013, p. 129). Estes e outros gêneros de livros circulavam ${ }^{10}$ por meio de vendedores ambulantes de livros de aluguel (kashihon'ya), que passavam em casas oferecendo aos clientes interessados os estoques de publicações mais recentes; após um certo período, os kashihon'ya retornavam nas casas para o recolhimento dos empréstimos e apresentação de outros títulos disponíveis. Como indica Buckland, é interessante notar que frequentemente eram as mulheres quem selecionavam os títulos apresentados por estes vendedores ambulantes - e, o que permitia um acesso direto aos livros eróticos (BUCKLAND, 2013, p. 144).

É notada uma produção de arte erótica mais intensa nos anos finais do período Edo - de 1820 a 1860 - em comparação aos anos de 1780 a 1820 (BUCKLAND, 2013, p. 129); em termos visuais, Buckland aponta "uma tendência para cores saturadas, e composições que se estendem até as bordas do campo da imagem, preenchendo todo o espaço com mobílias e apetrechos"11 (BUCKLAND, 2013, p. 129); e em termos de conteúdo, "os encontros sexuais tendem a ser mais dramáticos, com amantes perdidos num abandono extático, e um aumento no número de cenas com violência

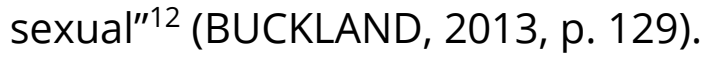

\section{A erótica de Utagawa Kunisada e a cultura das quatro estações}

Considerado um pintor ukiyo-e influente e de posição relevante em seu tempo e sobretudo posteriormente, Utagawa Kunisada nasceu em 1786, na cidade de Edo. Como de costume entre o meio artístico japonês, adotou diversos nomes para os

\footnotetext{
${ }^{10}$ Apesar de relevantes, os kashihon'ya não constituem o único modo de circulação de publicações.

${ }^{11}$ No original: "[...] a tendency towards saturated colours, and the compositions extend to the very edges of the picture field, filling the entire space with furnishings and accoutrements". Tradução nossa.

12 No original: "[...] the sexual encounters tend to be more dramatic, with lovers lost in ecstatic abandonment, and with an increased number of scenes of sexual violence". Tradução nossa.
} 


\section{artigos}

\section{A erótica de Utagawa Kunisada e a cultura das quatro estações}

diferentes momentos de produção na sua carreira, como Kinraisha, Gepparō, Ichiyūsai e Gototei, sendo Utagawa Kunisada e Toyokuni III aqueles pelos quais se tornou mais conhecido. Sua família oferecia serviços de travessia de rios por meio de barcos no distrito de Honjo, conhecido por ser um centro de atividades artísticas e de moradia de escritores, poetas, pintores e atores (IZZARD, 1993, p. 20), o que the possibilitou uma imersão no universo pictórico desde cedo. Suas primeiras produções permitiram um ganho de experiência que atraiu a atenção de Utagawa Toyokuni (1769-1825), mestre da escola Utagawa, reconhecida pelas estampas de retratos de atores e na qual Kunisada ingressaria como aprendiz. As primeiras impressões de seus desenhos circularam por volta de 1807 e lhe trouxeram um rápido reconhecimento, garantindo sua consolidação na década seguinte na posição de desenvolvedor de imagens teatrais. Além desta temática, Kunisada também produziu impressões de bijinga, as imagens de belas mulheres, cortesãs e profissionais do entretenimento; pinturas de locais famosos de cidades e províncias; e, posteriormente, pinturas de inspiração europeia caracterizadas pela adoção de técnicas como a perspectiva de ponto único, sombreamento, claro-escuro e outros (IZZARD, 1993, p. 28). Apesar de suas obras representarem majoritariamente o universo do teatro kabuki, Kunisada também produziu shunga em estampas únicas e livros ilustrados - como é o caso da fonte em análise. Durante sua carreira, atraiu e aceitou pupilos, trabalhou ao lado de mestres do ukiyo-e e acredita-se que sua produção totalize cerca de vinte mil estampas (IZZARD, 1993, p. 40). Faleceu em 1865, aos setenta e nove anos.

As fontes selecionadas para a análise são quatro estampas de Utagawa Kunisada, produzidas entre 1827 e 1829. As imagens pertencem aos quatro volumes dos livros "Contemplação das Quatro Estações do Amor", com as dimensões de 


\section{artigos}

\section{Giovanna Maia Tavares de Almeida}

$258 \times 190 \mathrm{~mm}$ quando fechados e $258 \times 355 \mathrm{~mm}$ quando abertos, sendo uma estampa de cada volume. ${ }^{13}$ Os volumes dos livros - assim como seu título - fazem referência às quatro estações do ano e os desenhos retratam cenas de cunho erótico em diferentes graus de explicitude entre casais. Os volumes Haru (Primavera) e Natsu (Verão) foram publicados no início de 1827, enquanto Aki (Outono) e Fuyu (Inverno) apenas em 1829 (BUCKLAND, 2013, p. 145); nos dois primeiros, as imagens se encontram logo no início dos livros, enquanto nos outros estão intercaladas com os textos. Enquanto as ilustrações foram produzidas por Kunisada, a parte textual contém histórias curtas e poemas relacionados às estações, e são de autoria de Enkōbō Tsukinari, um pseudônimo de Utei Enba II (1792-1863) (BUCKLAND, 2013, p. 145). Para a presente análise, a seleção das estampas foi pautada na possibilidade de apresentação de elementos que, sobretudo, façam referência à ambientação visual das quatro estações - por isso, a seleção de quatro estampas - e ainda de outras questões que frequentemente se verificam em obras de shunga. Apesar de ser algo recorrente em estampas de shunga, as presentes imagens não contêm nenhum tipo de produção textual em suas bordas ou centro - seja trechos da narrativa, poemas, kakiire $^{14}$, diálogos ou onomatopeias. As imagens possuem um grau elevado de detalhamento e uma ampla variedade de cores, demonstrando o estágio avançado das técnicas da xilogravura, a notável habilidade do pintor e dos outros agentes envolvidos na produção da obra. ${ }^{15}$

\footnotetext{
${ }^{13} \mathrm{Ao}$ total, são 30 estampas distribuídas aproximadamente por igual entre os quatro volumes que compõem a série de livros. Disponível em: https://research.britishmuseum.org/research/collection_online/collection_object_details.aspx?assetld= 761913001\&objectld=3799\&partld=1. Acesso em: 30 de abril de 2020.

${ }^{14}$ Traduzido como "notas", são os textos que acompanham as imagens.

15 Em xilogravuras ukiyo-e, fazem-se presentes diversos agentes em sua produção, como pintores, gravadores, impressores e editores. A função de Kunisada normalmente se constituía da produção dos desenhos e da supervisão da escala de cores.
} 


\section{artigos}

\section{A erótica de Utagawa Kunisada e a cultura das quatro estações}

Inevitável e intrínseca pela inserção natural do ser humano no espaço e no tempo, a temática envolvendo as quatro estações, no caso japonês, se faz extremamente abundante principalmente na literatura e na poesia - e se estende para além destas, como verificado nas artes visuais da pintura, escultura, xilogravura, cinema e arquitetura; ainda é possível percebê-la em âmbitos mais amplos, como na filosofia, na religião, na vida cotidiana e outros. Na obra em questão, as quatro estações presentes nas imagens se apresentam em diferentes representações e níveis - embora sempre presentes- e se inserem numa cultura que se distancia do período de produção da obra e, como colocado, não se restringe apenas à produção imagética. Consolidado como o período "clássico" na memória japonesa, o período Heian (794-1185) se configura, dentre outras diversas mudanças políticas e sociais, pelo poder da corte imperial e pela presença de uma sociedade aristocrática, inserida na burocracia estatal. Essa rememoração que atribui ao período a característica de "clássico" diz a respeito ao florescimento de diversas produções artísticas sobretudo ao que se refere à literatura e a poesia e, dentre outros aspectos, se faz presente a temática das quatro estações. Como aponta Shirane,

Foi na cultura de corte de Heian, na capital de Heian (Quioto), particularmente nos séculos $\mathrm{X}$ e $\mathrm{Xl}$, que se desenvolveu e se estabeleceu uma extremamente complexa e altamente codificada visão das quatro estações que se tornaria o modelo de elegância e de representação principalmente literária da natureza pelos próximos mil anos ${ }^{16}$ (SHIRANE, 2012, p. 205)

Na literatura, é possível apontar que "a progressão das estações do ano e sua apreciação passam a constituir temas ou enredos, como um perfeito entrelaçamento entre os fatos e o pano de fundo, tendo como eixo as estações" (FUKUDA, 1994, p.

\footnotetext{
${ }^{16}$ No original: "it was in the Heian court-based culture, in the capital of Heian (Kyoto), particularly in the tenth and eleventh centuries, that developed and established an extremely complex and highly codified view of the four seasons that would become the model of elegance and primarily literary representation of nature for the next thousand years". Tradução nossa.
} 


\section{artigos}

\section{Giovanna Maia Tavares de Almeida}

37). Em narrativas como Isemonogatari e, particularmente, em Genjimonogatari, as referências às estações do ano se fazem presentes desde os títulos de capítulos, as mudanças climáticas que condizem ao estado de espírito dos personagens e até as quatro alas da mansão Rokujō, com temáticas sazonais (FUKUDA, 1994, p. 38).

Recurso recorrente nas obras de ukiyo-e e shunga, a transposição de imagens, poemas, contos, literatura e elementos clássicos da mitologia japonesa em paródias de cenas eróticas serviu de inspiração para os artistas inovarem suas obras (HAYAKAWA, 2013, p. 103). Peculiaridades do período Edo, como o alto nível de alfabetização - sobretudo em centros urbanos - e a abordagem de cânones da literatura e poesia chinesas e japonesas como conteúdos escolares nas terakoya ${ }^{17}$, proporcionaram a familiarização da população japonesa com estas obras (HAYAKAWA, 2013, p. 103). Apesar das imagens em questão - pelo menos no âmbito iconográfico - não representarem uma obra canônica em específico, é notável a utilização de elementos típicos das estações, tida como uma característica clássica na cultura japonesa, aqui adaptada para criar uma ambientação visual num gênero de arte erótica.

Um elemento que se faz presente em todas as imagens dos shunpon em análise diz respeito à representação das genitálias nas cenas com elevados graus de explicitude - o que não se resume a essa obra, mas se mostra como uma predominância no gênero. É notável que as suas proporções, nos casos masculino e feminino, estejam aumentadas em comparação com a realidade. Isto indica um recurso tradicional de ênfase para evidenciar a atividade sexual (HAYAKAWA, 2013, p. 49), tanto em termos de tamanho quanto de detalhamento, o que é visto pelo nível

17 Escolas ligadas a templos que floresceram durante o período Edo. Seu currículo era pautado na leitura, escrita e aritmética. 


\section{artigos}

\section{A erótica de Utagawa Kunisada e a cultura das quatro estações}

dos detalhes da própria fisionomia dos órgãos e ainda dos pelos em seu entorno afinal, colocar estas regiões em evidência é um dos objetivos e pontos centrais destas obras, ao lado dos rostos e suas expressões, que também ocupam um espaço relevante nelas. Nota-se ainda que há uma certa proporção em comparação com o rosto, ao atentar-se ao tamanho, que se mantém em harmonia com a genitália. Levando em consideração estes fatores, é possível perceber um estranhamento na proporção dos corpos como um todo, sobretudo ao levar em consideração o posicionamento das pernas, braços, abdômen e pescoço. Sobre isso, Hayakawa comenta:

Um ponto central é que tanto as faces quanto a genitália são invariavelmente apresentados como uma composição equilibrada. Além disso, as imagens não focam apenas na genitália, mas sempre configuram as faces numa proporção igual. Ao enfocar o ato sexual e os rostos em paralelo, o impacto é que a composição dos corpos naturalmente se torna distorcida. ${ }^{18}$ (HAYAKAWA, 2013, p. 49)

Partindo para uma análise mais minuciosa, a estampa selecionada para o volume Haru, indicando a primavera, retrata a cena noturna de um homem sentado e, sobre ele, uma mulher de cócoras; encontram-se na varanda de madeira de uma casa, e o cenário se restringe ao céu da noite, uma lanterna de mão - e, na borda superior da imagem, galhos de cerejeira com flores e, majoritariamente, brotos prestes a desabrochar. O homem e a mulher, embora estejam localizados no mesmo quadrante da imagem, estão corporalmente distantes, próximos o suficiente apenas para o início da atividade sexual. A estampa sugere que ambos estão observando os graciosos ramos de cerejeira, com alguns brotos já florescidos e outros ainda fechados, mas possivelmente prestes a desabrochar - o que sugere relações com a

\footnotetext{
${ }^{18}$ No original: "A key point is that both the faces and the genitalia are invariably presented as a balanced composition. Furthermore, the images do not focus only on the genitalia, always setting the faces in equal proportion. In focusing on the sexual act and the faces in parallel, the impact is that the composition of the bodies naturally becomes distorted". Tradução nossa.
} 


\section{artigos}

\section{Giovanna Maia Tavares de Almeida}

atividade sexual na iminência de ser iniciada. A prática de observar cerejeiras, extensamente verificadas no âmbito artístico e cultural japonês, "iniciou já no período Nara [710-794] nos círculos aristocráticos, gradualmente se espalhando para uma sociedade plebeia no período Muromachi [1336-1573], e se tornou uma parte integral da vida urbana no período Edo"19 (SHIRANE, 2012, p. 213). A presença da lanterna de mão é interessante pois indica que foi levada até ali para cumprir um propósito - no caso, a atividade sexual; indica ainda se tratar de uma cena noturna, confirmado pela cor escura do céu, um procedimento inédito no período, de influência holandesa. Apesar de contemplar as cerejeiras, o casal ${ }^{20}$ também parece estar em estado de alerta. Notam-se sobrancelhas femininas maquiadas, quase apagadas, a sugerir o estado de mulher casada, também visível em sutil negror nos dentes em meio a entreabertos lábios. Estes fatores sugerem se tratar de um encontro furtivo, reforçado pelo local onde o casal se situa - uma varanda, provavelmente engawa, que normalmente se estende ao lado de fora das casas e permite o acesso a diversos cômodos, sendo propícia para esses encontros furtivos. Ambos vestem roupas tradicionais japonesas com estampas detalhadas; o obi (faixa que amarra o quimono) da mulher foi amarrado às costas, o que sugere não se tratar de uma cortesã - já que estas normalmente amarram o obi pela frente. Os penteados seguem os costumes da época: a mulher com um coque alto (shimada) ornamentado, e o homem com a parte superior da cabeça raspada, e o restante dos cabelos presos atrás (chonmage) - o que indica idade adulta, já que no período os cabelos masculinos eram raspados gradualmente de acordo com a idade.

\footnotetext{
19 No original: "began as early as the Nara period in aristocratic circles, gradually spread to a commoner society in the Muromachi period, and became an integral part of urban commoner life in the Edo period". Tradução nossa.

20 Para a presente análise, a utilização do termo "casal" se refere aos dois indivíduos que realizam uma atividade sexual entre si - não possuindo necessariamente um caráter matrimonial, ou mesmo de união formalizada jurídica ou religiosamente.
} 


\section{artigos}

\section{A erótica de Utagawa Kunisada e a cultura das quatro estações}

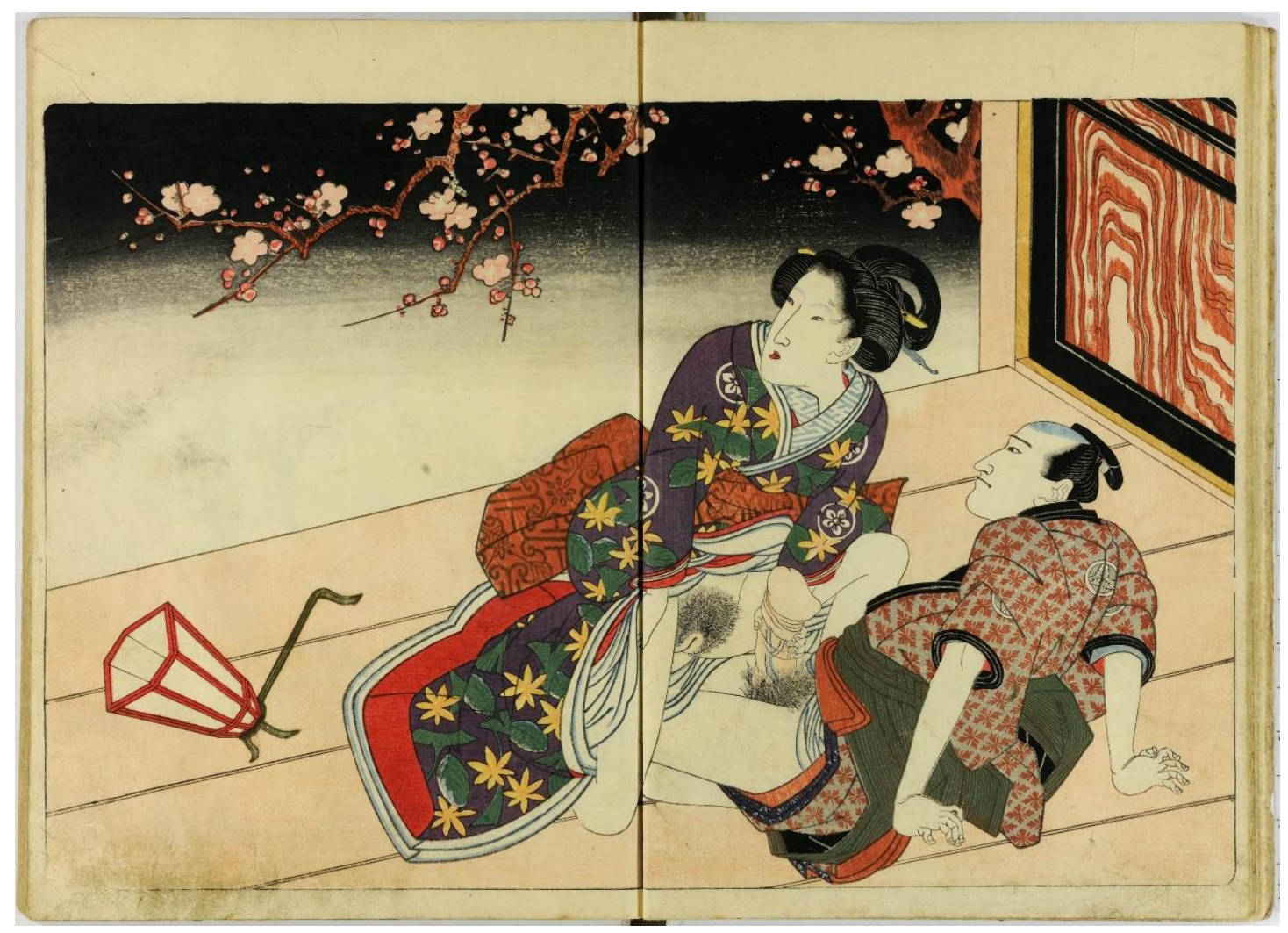

Imagem 1: estampa em xilogravura do volume Haru do livro “Contemplação das Quatro Estações do Amor", Utagawa Kunisada, 1827, 258×355mm. Fonte: British Museum, 2020.

Na sequência, o volume Natsu dispõe de uma estampa ilustrando a exaltação do amor num dia de verão. A cena retratada é de uma gueixa e seu amante consumando o ato sexual, localizados na varanda do andar superior de uma casa de chá (BUCKLAND, 2013, p. 148) - o homem em pé, e a mulher apoiada no parapeito de madeira. Aqui, a ambientação sazonal é pautada na típica chuva de verão intensa, que preenche todos os espaços da imagem com traços azuis na vertical - como aponta Buckland, formando "uma dinâmica poderosa criada pelo cruzamento das linhas verticais e diagonais da composição"21 (BUCKLAND, 2013, p. 148). Possivelmente atraídos e estimulados pela tempestade (BUCKLAND, 2013, p. 148), o casal aproveita o

21 No original: "A powerful dynamic is created by the criss-crossing vertical and diagonal lines of the composition". Tradução nossa. 


\section{artigos}

\section{Giovanna Maia Tavares de Almeida}

momento de frescor e umidade para exercer suas atividades. Há também a inserção de vegetações, com os bambus cobertos de folhagens ao canto direito e o típico pinheiro japonês abaixo do casal. O homem, que abraça a mulher por trás, esconde o rosto em suas costas, deixando visível apenas o olhar em profundo êxtase; em comparação com a estampa de Haru, a distância corporal deles é significativamente menor, pois o abraço e a posição das pernas permitem um contato físico mais expressivo. Nesta imagem, fica visível a distorção proposital dos corpos como recurso para se evidenciar o foco da imagem na atividade sexual, como mencionado anteriormente: aqui, as pernas parecem estranhamente curtas, as costas demasiadamente longas e a cabeça e pescoço, principalmente da mulher, posicionam-se de uma maneira que não atendem precisamente a uma representação realística. É notável ainda os detalhes na expressividade da ação do casal, como nos pés de ambos; a mulher, segurando fortemente no parapeito de madeira com um dos pés, e o homem tendo ambos flexionados em êxtase. Ambos vestem quimonos de tecido leve, possivelmente yukata, confeccionados para suportar as temperaturas do verão; e utilizam os penteados da imagem anterior - diferenciando apenas pelo cabelo da mulher, que possui mais ornamentos. 


\section{artigos}

\section{A erótica de Utagawa Kunisada e a cultura das quatro estações}

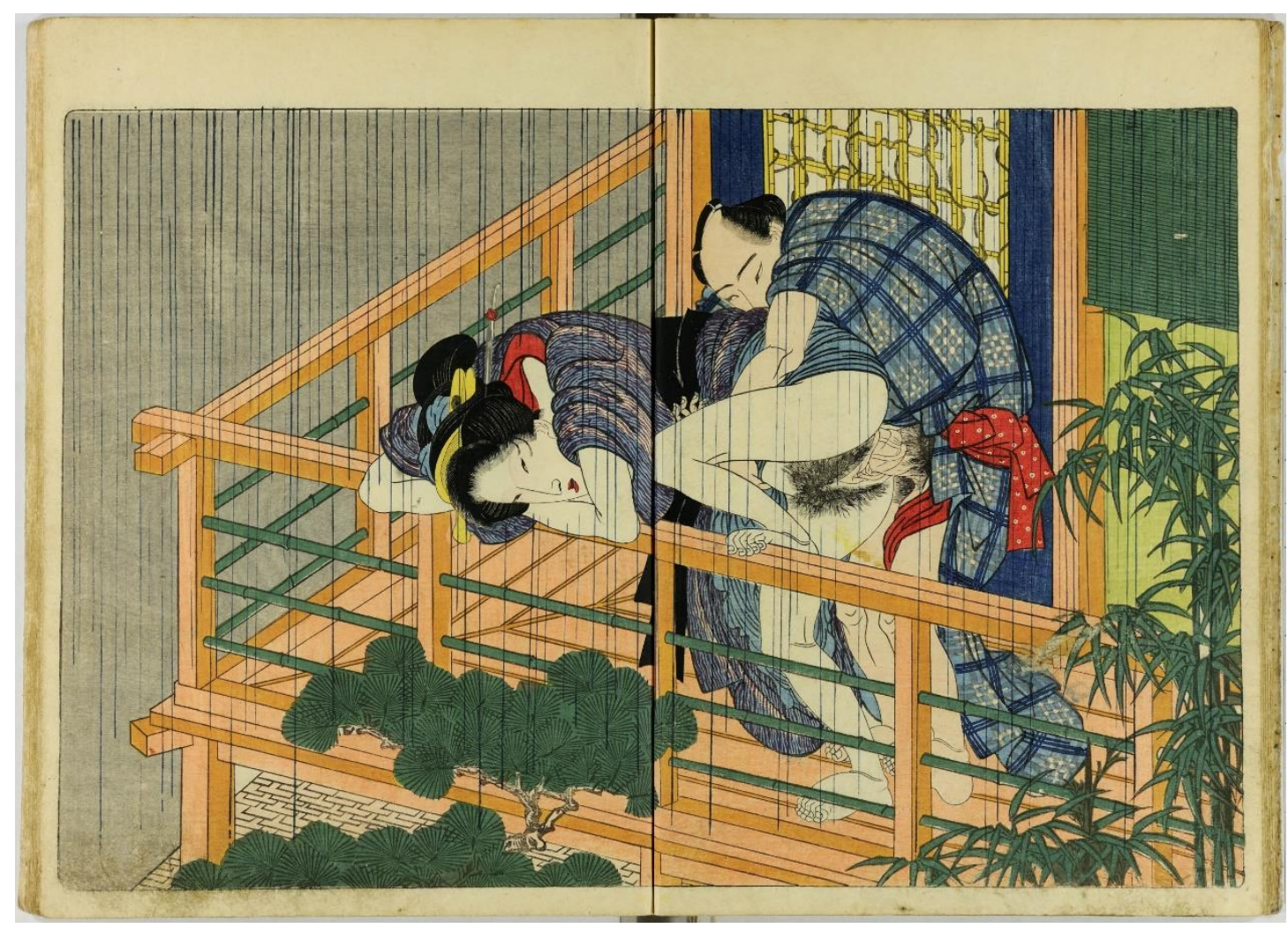

Imagem 2: estampa em xilogravura do volume Natsu do livro “Contemplação das Quatro Estações do Amor", Utagawa Kunisada, 1827, 258×355mm. Fonte: British Museum, 2020.

A estampa referente ao outono, do livro Aki, retrata a cena de um casal num ambiente externo, às margens de um rio. A ambientação sazonal é demonstrada sobretudo pela grande lua cheia de outono, que ocupa uma posição significativa no céu limpo. Diferentemente da típica representação outonal, pautada na transição das folhagens das árvores, a vegetação do desenho majoritariamente mantém tons verde escuros nos pinheiros japoneses, com algumas folhas de outras espécies em tons mais claros - principalmente as folhas momiji. Utilizando uma tradicional yukimi-dōrō (literalmente, "lanterna contemplação da lua") como apoio - uma lanterna de pedra acesa, o que indica se tratar de uma cena noturna, confirmado pela lua cheia no canto superior esquerdo - o casal se abraça pela frente e realiza a atividade sexual com um contato físico expressivo pela proximidade entre eles. A figura feminina 


\section{artigos}

\section{Giovanna Maia Tavares de Almeida}

utiliza os dois braços para abraçar o homem no pescoço; enquanto ele levanta a perna da parceira com um dos braços e se apoia na lanterna com o outro. Nota-se também na estampa a posição da perna e pé da figura feminina, entrelaçadas na perna do homem - novamente, nos esforços em se evidenciar a atividade sexual (mesmo que no caso os órgãos sexuais não ocupem um papel central no foco da cena), verifica-se uma distorção no posicionamento dos corpos, sobretudo ao atentarse para os membros inferiores da figura feminina. A respeito da cena se apresentar num ambiente externo, é notável que a prática sexual em espaços abertos, fora do ambiente fechado e íntimo de um aposento, ou ainda em momentos não propícios (como na estampa analisada em sequência), constitui-se como algo estimulante pelo perigo na exposição não desejada a terceiros; estas imagens são caracterizadas como kiwadoi (BUCKLAND, 2013, p. 42), literalmente "arriscado", "perigoso", "sugestivo". Apesar do casal não sugerir olhares atentos ou preocupados, eles se posicionam atrás de um pinheiro e da yukimi-dōrō, insinuando que possivelmente estão se escondendo. Nota-se ainda que, para esta análise, evitou-se utilizar o termo "mulher" para designar a figura feminina: além do fato de que os órgãos sexuais não estão representados em sua total explicitude, a figura feminina utiliza maquiagem vermelha na região dos olhos que, pela forma como está disposta, levanta a possibilidade de ser kumadori tipo de maquiagem utilizada por atores de teatro kabuki que, no período em questão, eram exclusivamente homens. Relações de cunho homoafetivo - homem a homem, ou mulher a mulher - também se configuram como uma temática recorrente em obras de shunga e são um campo de análise extremamente fértil pela abundância de fontes; nesta imagem em específico, não é possível afirmar categoricamente que seja este o caso - principalmente ao levar em consideração que a figura feminina não está 


\section{artigos}

\section{A erótica de Utagawa Kunisada e a cultura das quatro estações}

tipicamente caracterizada como onnagata ${ }^{22}$ ou wakashü ${ }^{23}$, o que é o usual em obras do gênero. Tal dúvida também é reforçada pela utilização do lenço, que dificulta a visualização do tipo de penteado utilizado pela figura feminina - já que este é um elemento que auxilia a identificar os sexos das personagens; wakashū normalmente trazem franja como mulheres, enquanto onnagata trazem partes da cabeça raspada como homens, mas geralmente escondidas por meio de um pequeno lenço roxo chamado musaraki bōshi. Nesse sentido, a sugestão e a ausência de interpretações definitivas sobre os elementos observados levantam a possibilidade de que o enigma a respeito do sexo da figura feminina possa ser intencional. Estes pontos são interessantes de serem salientados pois demonstra que, apesar das imagens se constituírem como um elemento relevante dentro dos shunpon pelas suas características visuais, frequentemente não fornecerão instrumentos suficientes para concluírem uma análise verticalizada por si sós. Finalmente, é relevante evidenciar a paisagem representada no plano ao fundo do casal: a representação da ponte sobre o rio, com traços delicados indicando sua fluidez, a vegetação e o relevo ao fundo compõem uma cena com atributos que se inserem na grande temática do ukiyo-e, da representação de locais urbanos e provincianos, e demonstram a habilidade do pintor em também reproduzir este conteúdo.

\footnotetext{
22 Em tradução literal, "forma de mulher", refere-se aos atores de teatro kabuki que performavam personagens femininas.

${ }^{23}$ Termo que se refere aos adolescentes do sexo masculino, que no período eram frequentemente considerados objetos de desejo sexual. Eram distinguidos por um corte de cabelo específico, com parte do cabelo raspado e o restante preso num coque alto.
} 


\section{artigos}

\section{Giovanna Maia Tavares de Almeida}

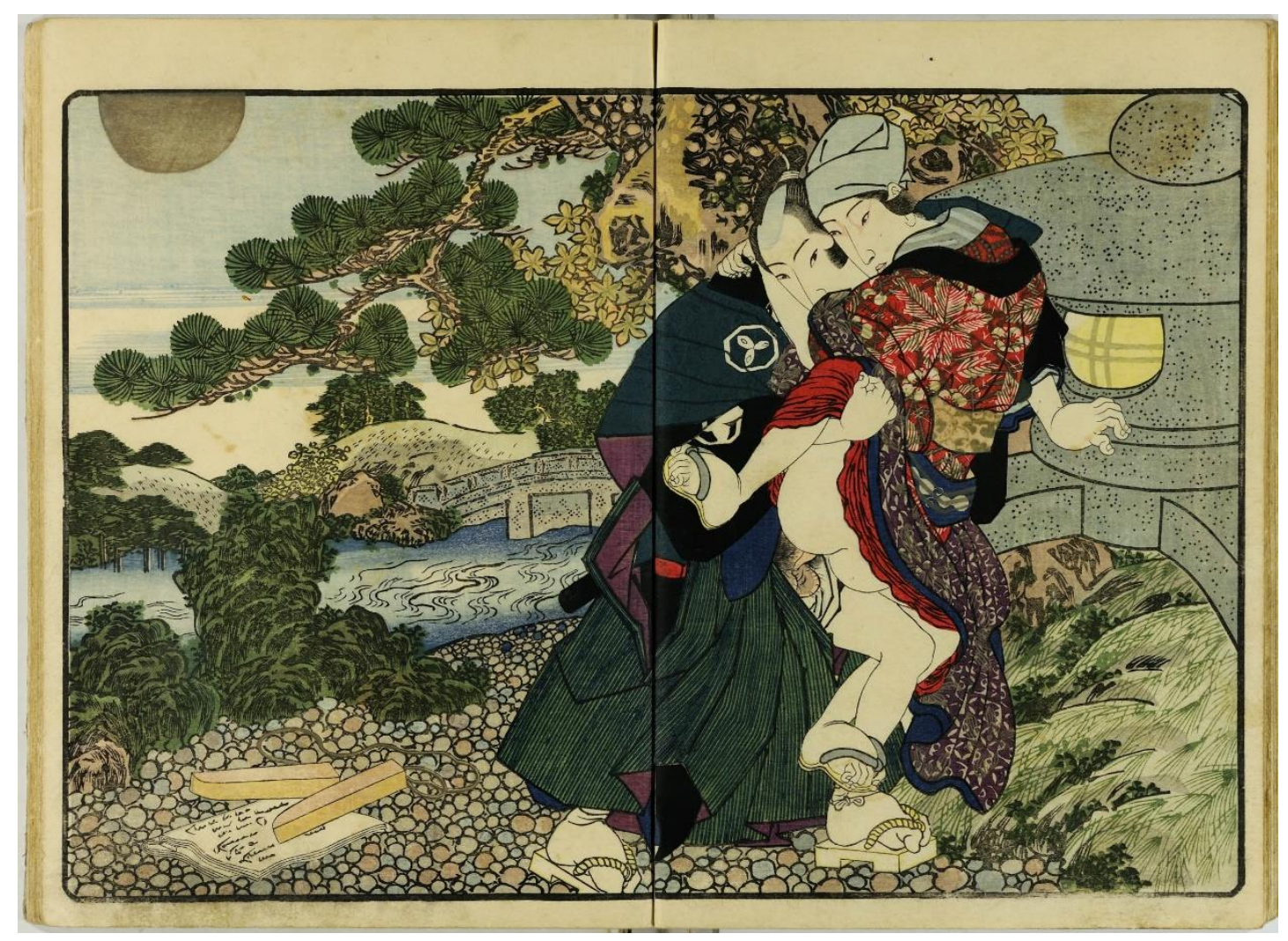

Imagem 3: estampa em xilogravura do volume Aki do livro "Contemplação das Quatro Estações do Amor", Utagawa Kunisada, 1829, 258×355mm. Fonte: British Museum, 2020.

Por fim, a estampa do livro Fuyu, representando o inverno, traz uma série de elementos que fazem referência a esta estação - além de possuir um notável caráter cômico. A cena é desenvolvida num ambiente interno, onde a atenção do recinto se volta para a utilização de kotatsu - um móvel tradicional japonês, que consiste numa mesa de madeira, um cobertor pesado, ou um futon, sobre ela e, embaixo, uma fonte de calor; as kotatsu são extensivamente utilizadas nos períodos mais frios, quando as pessoas sentam-se em volta da mesa e se cobrem com o cobertor impedindo que o ar quente se dissipe, mantendo-se aquecidas. A flor da estação está representada na pintura de botões de ameixeira branca. Na cena, estão presentes três indivíduos: um homem adormecido sobre um livro aberto, e um casal realizando "brincadeiras" eróticas por baixo da mesa - o homem desperto utilizando-se dos pés para provocar 


\section{A erótica de Utagawa Kunisada e a cultura das quatro estações}

a genital da mulher, que utiliza o cobertor para cobrir a boca e conter a surpresa, a satisfação e o riso. A cena traz um caráter cômico pelas brincadeiras ocorrerem num momento não propício para a realização desta atividade, provocando um regozijo pelo perigo - e pelo homem adormecido não estar ciente do que acontece por baixo dos panos. Como se lê nos papeis enrolados na estante, provavelmente trata-se de uma mulher sustentada (kakoi) pelo adormecido, em visita com um amigo que não Ihe faz jus. A respeito da comicidade em obras de shunga, Hayakawa afirma:

Vimos que um termo para shunga era warai-e (em tradução literal, "imagens de riso"). Warai-e pode significar a representação da vida sexual das pessoas, humorística ou satiricamente, o que faz sentido, mas vemos no shunga a representação explícita da vida sexual e o foco do riso é apresentado de forma crua e gráfica. Podemos dizer que no período Edo as pessoas viam a própria sexualidade como algo para rir ou apreciar.

É comum que o humor seja considerado baixo e inferior, mas o período Edo parece se deleitar com os prazeres do riso e o considerava essencial. É claro que há muito humor vulgar e irônico, mas as risadas que encontramos no ukiyo-e shunga mantêm todos como objetos iguais de diversão, e o foco também se volta para o espectador, enquanto rimos de nós mesmos e os pontos fracos da humanidade. É aqui que vemos a longa tradição de considerar sexo e warai como diversão, riso e prazer, e sua eficácia em suavizar a tendência humana de ser formal e rígida, e em controlar desejos sexuais poderosos e, muitas vezes, esmagadores. É muito importante para nós atualmente valorizar essa visão de sexo encontrada em ukiyo-e shunga. ${ }^{24}$ (HAYAKAWA, 2013, p. 37-38)

\footnotetext{
${ }^{24}$ No original: "We have seen that one term for shunga was "warai-e" (laughter pictures). Warai-e can mean the representation of peoples' sexual lives humorously or satirically, which makes sense, but we see in shunga the explicit depiction of sexual lives and the focus of the laughter is presented raw and graphically. We can say that in the Edo period people viewed sexuality itself as something to laugh at or enjoy. It is common that humor is considered base and low, but the Edo period seems to revel in the pleasures of laughter and considered it essential. Of course there is plenty of vulgar and derisive humor, but the laughter that we find in ukiyo-e shunga holds up everyone as equal objects of fun, and the focus goes around and around back to the viewer as well, as we laugh at ourselves and the foibles of humanity. It is here that we see the long tradition of considering sex and warai, fun, laughter, and pleasure, and its effectiveness in softening the human tendency to be formal and stiff, and in controlling powerful and often overwhelming sexual desires. It is very important for us today to treasure this view of sex found in ukiyo-e shunga". Tradução nossa.
} 


\section{artigos}

\section{Giovanna Maia Tavares de Almeida}

Além disso, como já mencionado e visto anteriormente, a prática sexual em espaços ou momentos não propícios se constitui como algo recorrente em obras de shunga; na cena representada, o risco de o casal ser pego é relativamente alto já que todos estão bem próximos no mesmo recinto - contribuindo e intensificando o caráter cômico da obra. Os livros espalhados, tanto embaixo do homem adormecido quanto ao lado do outro, sugerem que a atividade realizada anteriormente fora substituída por algo mais prazeroso para todos - seja o sono ou o sexo. Também é possível constatar nesta imagem a expressividade dos pés da mulher, que aperta com os dedos a perna do homem que está sendo utilizada para provocá-la. Nota-se que se trata de uma imagem em que os desenhos nos tecidos ocupam um espaço relevante na ambientação estética da obra: a estampa do cobertor por cima da kotatsu é altamente detalhada tanto nas formas quanto nas cores; os quimonos do homem e da mulher, com várias camadas e propício para o inverno, possuem estampas de listras verticais - as quais eram consideradas o máximo da finesse a partir do século XVII, especialmente na moda citadina. Novamente, os penteados seguem os estilos já retratados nas outras imagens aqui analisadas, com o detalhe de que o homem desperto tem a parte superior de seu cabelo raspado - o que indica se tratar de um jovem adulto - enquanto o homem adormecido parece ser naturalmente calvo, possivelmente indicando uma idade mais avançada. 


\section{artigos}

\section{A erótica de Utagawa Kunisada e a cultura das quatro estações}

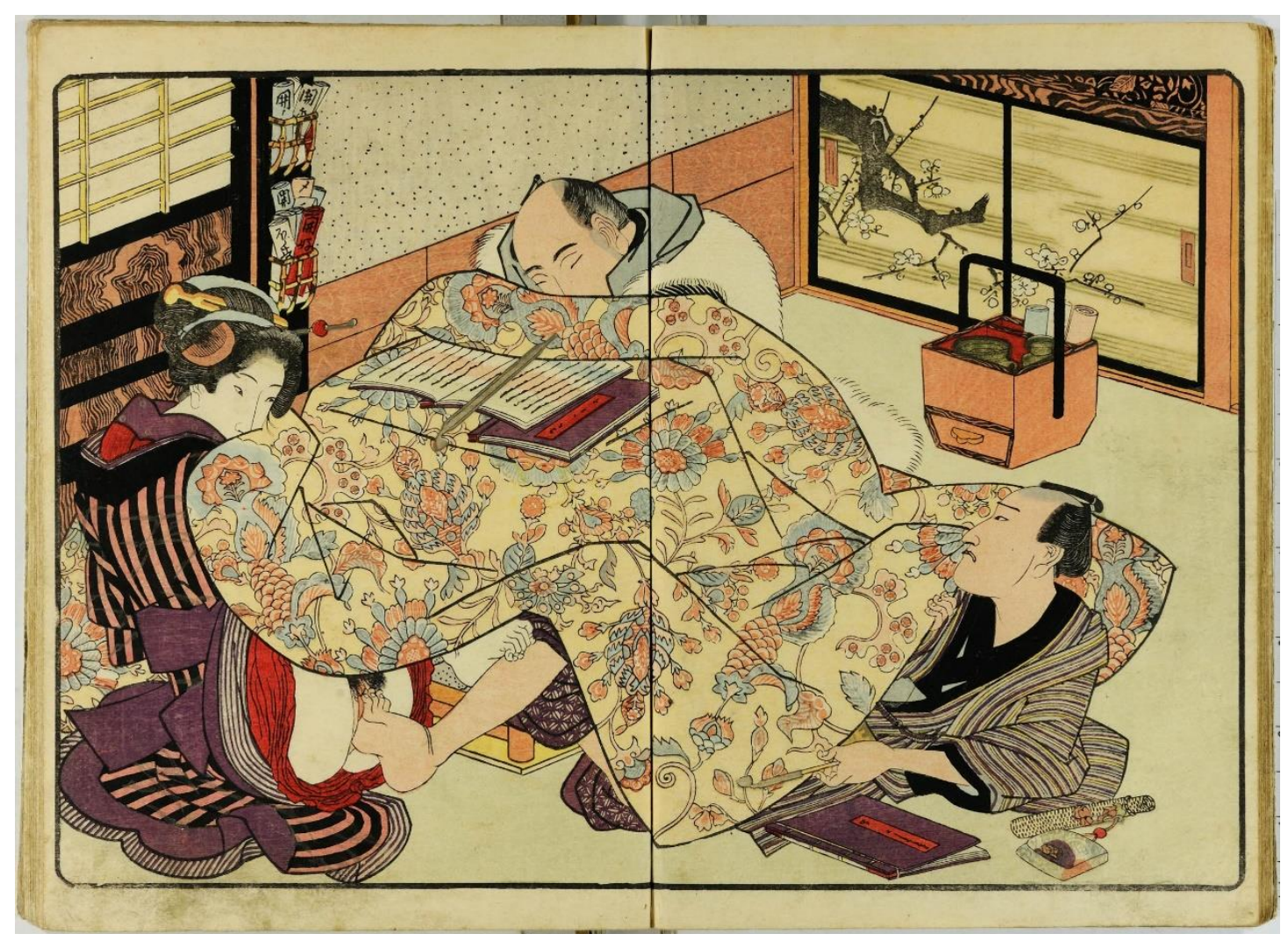

Imagem 4: estampa em xilogravura volume Fuyu do livro "Contemplação das Quatro Estações do Amor", Utagawa Kunisada, 1829, 258×355mm. Fonte: British Museum, 2020.

Dessa forma dão-se os esforços de Kunisada para elaborar a ambientação visual das imagens eróticas que acompanham os textos dos livros. É notável a utilização de recursos artísticos que se diferenciam das estratégias linguísticas - e trazem uma expressividade singular e condizente com o que se faz representar, seja pelos detalhes ou pelo todo.

\section{Conclusão}

Em suma, a análise das estampas de Utagawa Kunisada nos volumes de "Contemplação das Quatro Estações do Amor" se propôs a explorar brevemente o panorama do gênero compreendido atualmente como shunga; trazer uma contextualização histórica horizontal a respeito do período Edo, sobretudo nas questões referentes aos campos da política e da arte; pontuar sucintamente as 


\section{artigos}

\section{Giovanna Maia Tavares de Almeida}

produções e a trajetória de vida do autor; compreender brevemente a chamada "cultura das quatro estações" no caso japonês, que possui suas raízes no campo da literatura e poesia com uma distância temporal significativa do momento de produção da obra em questão; apontar como as obras de shunga se utilizaram de elementos clássicos da cultura japonesa em adaptações para um gênero de arte erótica; analisar as estampas levando em consideração os pontos centrais que compõem os elementos visuais que trazem expressividade ao que está sendo retratado, atentando-se ainda para as tendências encontradas em obras do gênero; e, sobretudo, como o pintor se utilizou destes recursos imagéticos para exprimir as referências às mudanças sazonais em suas imagens de cunho erótico.

As imagens shunga, embora sejam frequentemente associadas à produção textual, de modo algum podem ser consideradas como simples ilustrações: elas transmitem sentidos através da ornamentação, das formas e da frequência e da utilização de outros recursos imagéticos que se diferenciam das estratégias linguísticas para a inserção do leitor no universo da narrativa. Como visto na presente análise, as estampas se utilizam de elementos que compõem um notável quadro de expressões visuais: seja por meio da distorção proposital dos corpos para evidenciar a atividade sexual, da ambientação física dos personagens e dos recintos, do cenário dos ambientes ou do mobiliário e apetrechos, exprime-se através dos detalhes e do todo a proposta primordial da obra - a exaltação do amor nas diferentes estações do ano. Esta temática da representação sazonal teve suas origens no período Heian, caracterizado pela cultura da corte e da sociedade aristocrática e rememorado como sendo o período "clássico" na memória japonesa pelo florescimento de diversas produções artísticas, sobretudo no que se refere à literatura e a poesia - nas quais se 


\section{artigos}

\section{A erótica de Utagawa Kunisada e a cultura das quatro estações}

mostram tais representações, que se tornaram o modelo de elegância pelos séculos seguintes (SHIRANE, 2012, p. 205).

Numa análise mais minuciosa, no volume Haru a representação sazonal é revelada principalmente através dos tradicionais ramos de cerejeira observados pelo casal, com alguns brotos já florescidos e outros prestes a desabrochar - indicando também uma possível relação com a atividade sexual na iminência de ser iniciada; viu-se ainda que a prática de observar cerejeiras teve sua origem no período Nara e espalhou-se gradualmente até sua consolidação no período Edo (SHIRANE, 2012, p. 213), indicando outra referência a um elemento clássico na cultura japonesa. No volume Natsu, a forte chuva é a referência ao verão, com seus pingos de chuva preenchendo todos os espaços da imagem e criando uma ambientação visual poderosa. Em Aki, diferentemente da representação usual da transição das folhagens das árvores, a representação do outono se revela pela grande lua cheia, que ocupa uma porção significativa no céu da imagem; além disso, notou-se a presença de outros elementos recorrentes em obras do gênero, como o estímulo pela realização da atividade sexual em ambientes ou momentos não propícios a qual se atribui a característica de kiwadoi e ainda a sugestividade pela não identificação precisa do sexo da figura feminina pela maneira que ela se caracteriza. Por fim, no volume Fuyu, as representações sazonais são centradas na utilização de uma kotatsu, móvel tradicional japonês extensivamente utilizado em períodos mais frios por proporcionar aquecimento aos usuários, além da representação da flor da estação, os botões e ameixeira branca; nesta estampa também é possível verificar a prática num momento não propício, pela "brincadeira" sexual ser realizada por baixo da kotatsu e sem o conhecimento de um terceiro presente no recinto, adormecido - gerando ainda uma situação cômica ao leitor, também recorrentes em obras de shunga (e que, por esse motivo, também eram conhecidas como warai-e, "imagens de risada"). 


\section{artigos}

\section{Giovanna Maia Tavares de Almeida}

Vale ressaltar que as imagens por si só não permitem inferir respostas definitivas e definidoras na busca por uma compreensão da obra em sua totalidade: como visto pela estampa em Aki, há nuances que sugerem possibilidades e sugestividades que não se confirmam concretamente somente pela análise iconográfica - e, nesse sentido, a aliança com a análise da parte textual se torna deveras proveitosa.

Faz-se necessário salientar novamente que uma visão retroativa sobre a utilização de shunga, somada a uma lente exotizante e a uma errônea percepção que equipara este tipo de produção ao uso atual da pornografia, escurecem as possibilidades de estudo que este rico material proporciona sobre o entendimento da arte, literatura, cultura e sociedade japonesa do Edo. Como visto anteriormente, as

obras de shunga variavam extensivamente em questão de público - homens e mulheres, jovens e adultos, citadinos e agricultores - e de uso - servindo como objetos com poderes espirituais capazes de afastar incêndios, trazer segurança em batalhas, promover a fertilidade e ainda serviam como presentes de casamento às jovens noivas (HAYAKAWA, 2013, p. 17-19).

Outro fator para ser levado em consideração diz respeito à inclusão de shunga como uma forma de arte relevante dentro das produções de pintores que vieram a ser prestigiados posteriormente, tanto no Ocidente quanto no Oriente. Dentre notáveis pintores do Edo verifica-se que há uma produção significativa de shunga e que, muitas vezes, são pouco mencionadas frente as suas outras produções. Tomando o caso de Kunisada como exemplo, é certo que suas produções mais reconhecidas referem-se principalmente ao universo do teatro kabuki, além de se estenderem para as imagens de belas mulheres, contos do folclore, fauna e flora e etc.; apesar disso, pouco se refere a sua produção de obras que possuem cenas 


\section{artigos}

A erótica de Utagawa Kunisada e a cultura das quatro estações explícitas e implícitas de atividade sexual, mesmo que estas se configurem como algo minoritário dentro de sua produção artística.

\section{Referências Bibliográficas}

CORDARO, Madalena Natsuko Hashimoto. A erótica japonesa na pintura \& na escritura dos séculos XVII a XIX. São Paulo: Edusp, 2017.

As estampas xilográficas Shunga: metonímias do corpo erótico. Estudos Japoneses, São Paulo, n. 23, pp. 63-73, 2003.

BUCKLAND, Rosina. Shunga: Erotic Art in Japan. Nova York: The Overlook Press, 2013.

FUKUDA, Hiaeichi. As estações do ano e sua concepção na literatura japonesa. Estudos Japoneses. São Paulo, n. 15, pp. 35-43, 1995.

HALL, John Whitney; MCLAIN, James L.. The Cambridge History of Japan. Vol. 4. Cambridge: Cambridge University Press, 1993.

HAYAKAWA, Monta; GERSTLE C. Andrew. Who Were the Audiences for 'Shunga'? Japan Review, Kyoto, n. 26, pp. 17-36., 2013.

Shunga: ten questions and answers. Kyoto: International Research Center for Japanese Studies, 2013.

ISHIGAMI, Aki; BUCKLAND, Rosina. The Reception of 'Shunga' in the Modern Era: From Meiji to the Pre-WWII Years. Japan Review. Kyoto, n. 26., pp. 37-55, 2013.

MORSE, Anne Nishimura. Japanese art: Evolving definitions. Arts of Japan. MFA Highlights. Boston: Museum of Fine Arts, 2008.

IZZARD, Sebastian. Kunisada's World. Nova York: Japan Society Gallery, 1993. 


\section{artigos}

Giovanna Maia Tavares de Almeida

OKANO, Michiko. Arte japonesa e suas supostas peculiaridades: espaços de onde se lança o olhar. Brasília: Anais do XXXII Colóquio CBHA 2012, Direções e sentidos da História da Arte, 2012, pp. 1127-1150.

Fronteira e diálogo na arte japonesa. Campinas: VI Encontro de História da Arte, 2010, pp. 370-380.

SHIRANE, Haruo. Japan and the Culture of the Four Seasons: Nature, Literature and the Arts. Nova York: Columbia University Press, 2012.

TOBY, Ronald P. Reopening the Question of Sakoku: Diplomacy in the Legitimation of the Tokugawa Bakufu. The Journal of Japanese Studies, Tokyo, v. 3, n. 2, 1977.

\section{Imagens}

Imagem 1: UTAGAWA KUNISADA. Haru, 1827, 258×355mm. Londres, British Museum, 2020. Disponível em:

https://research.britishmuseum.org/research/collection online/collection object detai Is/collection image gallery.aspx?partid=1\&assetid=761792001\&objectid=3799. Acesso em: 30 de abril de 2020.

Imagem 2: UTAGAWA KUNISADA. Natsu, 1827, 258x355mm. Londres, British Museum, 2020. Disponível em:

https://research.britishmuseum.org/research/collection online/collection object detai Is/collection image gallery.aspx?partid=1\&assetid=762232001\&objectid=3799 Acesso em: 30 de abril de 2020.

Imagem 3: UTAGAWA KUNISADA. Aki, 1829, 258×355mm. Londres, British Museum, 2020. Disponível em:

https://research.britishmuseum.org/research/collection online/collection object detai Is/collection image gallery.aspx?partid=1\&assetid=762902001\&objectid=3799. Acesso em: 30 de abril de 2020. 


\section{artigos}

A erótica de Utagawa Kunisada e a cultura das quatro estações

Imagem 4: UTAGAWA KUNISADA. Fuyu, 1829, 258×355mm. Londres, British Museum, 2020. Disponível em:

https://research.britishmuseum.org/research/collection online/collection object detai Is/collection image gallery.aspx?partid=1\&assetid=763804001\&objectid=3799. Acesso em: 30 de abril de 2020. 